\title{
Mortality from Cardiovascular Diseases among Diabetics
}

\author{
A. S. Królewski, A. Czyzyk, D. Janeczko, and J. Kopczyński \\ IIIrd Department of Internal Diseases and Department of Epidemiology, Medical Academy, Warsaw, Poland
}

\begin{abstract}
Summary. A retrospective analysis of a cohort of 5210 diabetic patients revealed a mortality rate 1.3 times higher than in the general population of Warsaw. The higher death rate in the cohort under study was mainly due to an excess mortality from coronary heart disease and cerebrovascular disease. The excess mortality was greater in men than in women. The risk of death from cardiovascular diseases was higher among the patients with early onset diabetes. Mortality from cerebrovascular disease was highest in patients treated with insulin, intermediate in the group treated with oral drugs, and lowest in the group treated only with diet. The mortality ratio from coronary heart disease in men was not related to the method of hypoglycaemic therapy given at the onset or during the course of the diabetes. In women, the highest mortality was in the group treated with insulin, intermediate in the group treated with oral agents, and lowest in the group treated with diet only.
\end{abstract}

Key words: Diabetes mellitus, mortality, coronary heart disease, cerebrovascular disease, hypoglycaemic therapy, cohort studies.

Despite advances in the therapy and management of diabetes, patients suffering from this disease continue to be exposed to an increased risk of premature death. The high death rate is due to acute or late complications of diabetes, the most important of which are the macroangiopathies [1-5]. In 1972, an epidemiological study was undertaken in Warsaw on the fate of diabetic patients and possibly related factors [6].

One of the aims of this study was to determine whether mortality from cardiovascular diseases is higher among diabetics than in the general population of Warsaw. The relationship between mortality and the type of hypoglycaemic treatment has also been investigated.

\section{Methods}

In Warsaw four specialised outpatient clinics are available for treatment of diabetic patients. Between Jan. 1, 1963 and June 30, 1973, about 13000 patients were registered at these clinics. After a review of the clinic records, 5666 patients qualified for admission to a study on the fate of diabetic patients. The group consisted of patients born between 1905 and 1956 who, at the time of registration in the clinics, were residents of Warsaw, and in whom diabetes was diagnosed between Jan. 1963 and June 1973. At the time of diagnosis all patients had blood glucose levels of at least $140 \mathrm{mg} / 100 \mathrm{ml}$ either in the fasting state, $2 \mathrm{~h}$ after meals or after oral administration of glucose.

(In Warsaw, during this period the "true" glucose was mostly measured by King's or by the ortho-toluidine method).

The present study covers only those patients who at the time of diagnosis of diabetes were aged 30-68 years, i. e. a group of 5261 patients. The remaining 405 patients in whom diabetes was diagnosed before the age of 30 years were not included in the analysis.

The fate of the patients was followed from diagnosis of diabetes (registration in the clinics), until Dec. 31, 1973. In the event of death during the period of observation, the date, place and cause of death were recorded, derived from death certificates. 
The mode of treatment of diabetes was determined from the documents of the outpatient clinics or hospitals, and interviews with patients.

According to the type of hypoglycaemic therapy given during the first six months after diagnosis of diabetes, the patients were divided into the following subgroups:

- dietetic treatment - this subgroup comprises patients who during the first six months required no drug treatment being treated only with diet;

- insulin treatment - this subgroup includes patients who in the course of the first six months after diagnosis required daily injections of insulin lasting at least two weeks;

- treated with oral drugs - this subgroup includes the remaining patients who received oral drugs during the first six months and who could not be included in either of the preceding subgroups.

No subdivision of patients treated with oral agents has been attempted since derivatives of sulphonylurea and biguanide were introduced in Poland at different times (early 1960s for the former, and early 1970 s for the latter).

In all patients the duration of diabetes was estimated. By summing the number of years of diabetes, the numbers of patient-years of observation and of hypoglycaemic treatment were obtained.

Deaths in the course of observation were classified into subgroups of hypoglycaemic therapy prescribed during the six months preceding death.

In total group, the numbers of deaths were calculated, as well as numbers of deaths expected on the assumption of an equal probability of death with inhabitants of Warsaw in the years 1963-1973. The ratio of the number of actually observed deaths to the number expected was computed to constitute the so-called o/e ratio.
Further analysis concerned the relation between the type of hypoglycaemic therapy employed initially, or later, and mortality. Since mortality was related to sex, age and duration of diabetes, the influence of these variables on compared therapeutic effects was eliminated by standardisation [7]. Elimination was carried out in two phases. In the first phase, the material was divided into subgroups according to age, sex and duration of diabetes (Table 1). Within these classes, the actual number of deaths in relation to different categories of treatment was determined, and the number of predicted deaths was calculated assuming lack of any effect of treatment on mortality. In the second phase, in each subgroup of treatment, predicted and actually observed deaths were summed up along the axes of 'age' and 'duration of diabetes', to form a single summary contingency table containing the totals for each sex. For the summary table, values of Chi - square were determined in order to evaluate significance of differences in the predicted and observed numbers. The ratios of the number of observed to predicted deaths within different therapeutic categories multiplied by 100 were equivalent to the standardised mortality ratios, illustrated graphically in the figures.

\section{Results}

The fate of 5210 diabetics was determined. Information was unavailable in 51 cases. Since their sex, age, duration of diabetes and type of hypoglycaemic therapy were similar to the analyzed group, it can be assumed that no bias was introduced by their elimination from the analysis.

Table 1 presents the distribution of the investigated cohort by age at time of diagnosis of diabetes,

Table 1. Mortality rate among 5210 diabetics according to sex and age at diagnosis of diabetes mellitus (traced to the end of 1973)

\begin{tabular}{|c|c|c|c|c|c|c|c|c|c|c|c|}
\hline \multirow{4}{*}{$\begin{array}{l}\text { Age at } \\
\text { diagnosis } \\
\text { of diabetes } \\
\text { mellitus }\end{array}$} & \multicolumn{11}{|c|}{ Date of diagnosis of diabetes mellitus } \\
\hline & \multicolumn{4}{|c|}{$1963-1966^{\mathrm{a}}$} & \multicolumn{3}{|l|}{$1967-1970^{b}$} & \multicolumn{4}{|c|}{ 1971-mid. $1973^{\mathrm{c}}$} \\
\hline & \multicolumn{2}{|c|}{$\mathrm{M}$} & \multicolumn{2}{|l|}{$\mathrm{F}$} & $\mathrm{M}$ & \multicolumn{2}{|l|}{$\mathrm{F}$} & \multicolumn{2}{|c|}{$\mathrm{M}$} & \multicolumn{2}{|l|}{$\mathrm{F}$} \\
\hline & $\overline{(n)}$ & $\begin{array}{l}\text { mortality } \\
\%\end{array}$ & $\overline{(n)}$ & $\begin{array}{l}\text { mortality } \\
\%\end{array}$ & (n) $\underbrace{\text { mortality }}_{\%}$ & (n) & $\begin{array}{l}\text { mortality } \\
\%\end{array}$ & (n) & $\begin{array}{l}\text { mortality } \\
\%\end{array}$ & $\overline{(n)}$ & $\begin{array}{l}\text { mortality } \\
\%\end{array}$ \\
\hline $30-39$ & $(88)$ & 4.6 & $(78)$ & 3.9 & (96) 4.2 & & 2.4 & (53) & 1.9 & $(42)$ & 2.4 \\
\hline $40-49$ & (144) & 13.2 & (158) & 4.4 & $(275) 6.6$ & $(25$ & 2.7 & $(222)$ & 2.7 & $(157)$ & 0.7 \\
\hline $50-59$ & $(302)$ & 20.2 & $(436)$ & 11.7 & (411) 10.5 & $(47$ & 4.5 & $(246)$ & 2.1 & $(316)$ & 1.0 \\
\hline $60+$ & $(31)$ & 29.0 & $(39)$ & 23.1 & (287) 12.6 & $(37$ & 9.0 & $(284)$ & 15.0 & (359) & 2.5 \\
\hline Total & $(565)$ & 16.5 & (711) & 9.8 & (1069) 9.5 & $(118$ & 5.4 & $(805)$ & 3.6 & $(874)$ & 1.6 \\
\hline
\end{tabular}

a the oldest persons at diagnosis of diabetes mellitus were at 61 years

b the oldest persons at diagnosis of diabetes mellitus were at 65 years

c the oldest persons at diagnosis of diabetes mellitus were at 68 years 
date of diagnosis, sex, and mortality during the observation period. In each subgroup of duration, the mortality in men was twice that in women.

In all, 370 patients died, including 223 men and 147 women. The causes of death are recorded in Table 2. Cardiovascular diseases accounted for $52 \%$ of deaths in men and $36 \%$ in women.

Analysis revealed a 1.3-fold excess mortality among diabetics. The excess mortality in men and women was similar (Table 3).

Comparison of mortality from coronary heart disease and cerebrovascular disease showed a much higher excess mortality among diabetics than had been the case for general mortality (Table 3). Among diabetic men, deaths from coronary heart disease were twice that of the general population, and in diabetic women 1.8 times higher. Mortality from cerebrovascular disease was 3.0 times higher in diabetic men and 1.5 times in women, compared with mortality from these causes in the general population of Warsaw (Table 3). However, comparison of excess mortality between the diabetic patients and the general population, after exclusion of deaths due to cardiovascular diseases, revealed that the number of deaths among diabetics was equal to the number of deaths occurring in the general population. We concluded that the excess of deaths in this cohort of diabetic patients was mainly a result of higher mortality from cardiovascular diseases.

The excess mortality from cardiovascular diseases was related to age at the time when diabetes was discovered. In the group of patients in whom diabetes was discovered between ages 50 and 68 years, the excess mortality was half that in the group of patients in whom diabetes was discovered between the ages of 30 and 49 years (Table 3 ).

Overall, excess mortality in diabetic patients was clearly related to the type of initial treatment of diabetes. Highest mortality ratios were observed in

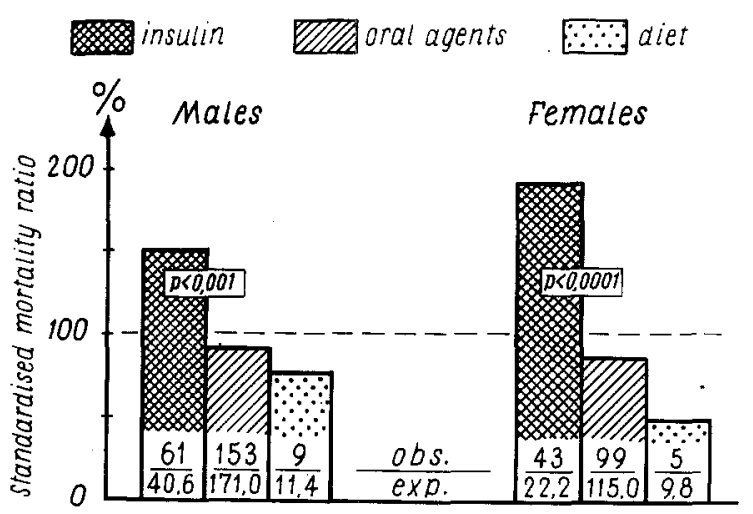

Fig. 1. Standardised mortality ratios from all causes among diabetics according to sex and initial hypoglycaemic treatment. Among men 477 were treated with insulin, 1836 with oral agents and 124 with diet only. Among women 392 were treated with insulin, 2196 with oral agents and 183 with diet only

Table 2. Deaths among diabetics according to sex and cause of death

\begin{tabular}{|c|c|c|c|c|}
\hline \multirow[t]{2}{*}{ Causes of deaths } & \multicolumn{2}{|c|}{$\begin{array}{l}\text { Male } \\
(2439)\end{array}$} & \multicolumn{2}{|c|}{$\begin{array}{l}\text { Female } \\
(2771)\end{array}$} \\
\hline & $\mathbf{n}$ & $\%$ & $\mathbf{n}$ & $\%$ \\
\hline $\begin{array}{l}\text { Myocardial infarction } \\
(410-414)\end{array}$ & 45 & 20.2 & 19 & 12.9 \\
\hline Sudden death (795) & 23 & 10.3 & 6 & 4.1 \\
\hline $\begin{array}{l}\text { Other heart diseases } \\
(420-429)\end{array}$ & 17 & 7.6 & 12 & 8.2 \\
\hline $\begin{array}{l}\text { Cerebrovascular disease (CVD) } \\
\quad(430-438)\end{array}$ & 31 & 13.9 & 16 & 10.9 \\
\hline Cirrhosis (571) & 18 & 8.1 & 12 & 8.2 \\
\hline Cancer (140-209) & 38 & 17.0 & 33 & 22.4 \\
\hline Accidents & 10 & 4.5 & 3 & 2.0 \\
\hline Other causes & 38 & 17.0 & 34 & 23.1 \\
\hline Causes unknown & 3 & 1.3 & 12 & 8.2 \\
\hline Total & 223 & 100.0 & 147 & 100.0 \\
\hline
\end{tabular}

( ) In parentheses there are numbers of causes of deaths according to VIII-th Revision of International Statistical classification of Diseases, Injuries and Causes of Death

Table 3. Comparison of the mortality rates among diabetics with that of the Warsaw inhabitants, according to sex, age at diagnosis of diabetes mellitus and causes of deaths

\begin{tabular}{|c|c|c|c|c|c|c|c|c|c|c|}
\hline \multirow{2}{*}{\multicolumn{2}{|c|}{$\begin{array}{l}\text { Age at diagnosis } \\
\text { of diabetes } \\
\text { mellitus }\end{array}$}} & \multicolumn{3}{|c|}{ Deaths from CHD } & \multicolumn{3}{|c|}{ Deaths from CVD } & \multicolumn{3}{|c|}{ All deaths } \\
\hline & & \multirow{2}{*}{$\begin{array}{l}\text { observed } \\
18\end{array}$} & \multirow{2}{*}{$\frac{\text { expected }^{\mathrm{a}}}{5.3}$} & \multirow{2}{*}{$\begin{array}{l}\mathrm{o} / \mathrm{e} \\
\text { ratio }\end{array}$} & \multirow{2}{*}{$\frac{\text { observed }}{4}$} & \multirow{2}{*}{$\frac{\text { expected }^{\mathrm{a}}}{1.0}$} & \multirow{2}{*}{$\begin{array}{l}\begin{array}{l}\text { o/e } \\
\text { ratio }\end{array} \\
4.00\end{array}$} & \multirow{2}{*}{$\frac{\text { observed }}{52}$} & \multirow{2}{*}{ expected $^{\mathrm{a}}$} & \multirow{2}{*}{$\begin{array}{l}\text { o/e } \\
\text { ratio }\end{array}$} \\
\hline $30-49$ & M & & & & & & & & & \\
\hline & $\mathrm{F}$ & 6 & 1.8 & 3.33 & 3 & 0.8 & 3.75 & 21 & 13.2 & 1.61 \\
\hline \multirow[t]{2}{*}{$50-68$} & $\mathbf{M}$ & 67 & 38.2 & 1.75 & 27 & 9.5 & 2.84 & 171 & 145.1 & 1.17 \\
\hline & $\mathrm{F}$ & 31 & 19.3 & 1.60 & 13 & 10.1 & 1.30 & 126 & 102.9 & 1.22 \\
\hline \multirow[t]{2}{*}{ Total } & $\mathbf{M}$ & 85 & 43.5 & 1.95 & 31 & 10.5 & 2.95 & 223 & 169.5 & 1.31 \\
\hline & $\mathrm{F}$ & 37 & 21.1 & 1.75 & 16 & 10.9 & 1.47 & 147 & 116.1 & 1.27 \\
\hline
\end{tabular}

a mortality rates in Warsaw in the period 1963-1973 were used as standard. CHD and CVD see Table 2 


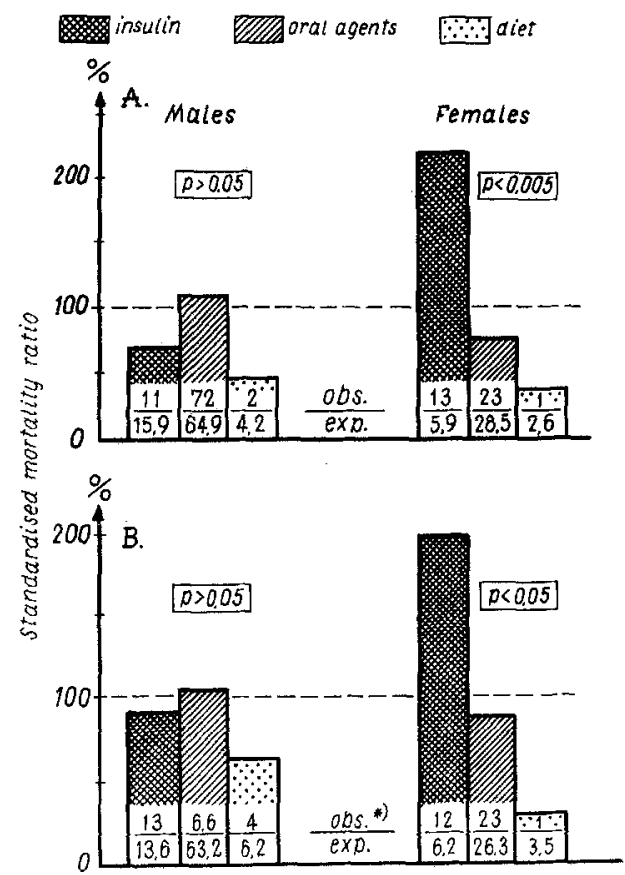

Fig. 2. Standardised mortality ratios from coronary heart disease among diabetics according to sex and A) initial hypoglycaemic treatment, B) hypoglycaemic treatment given during the course of the diabetes. Number of person-years of each treatment are presented in Table 4. * Two deaths among men and one among women occurred when treatment was not known and they were excluded from analysis

Table 4. Age-standardised mortality rates from coronary heart disease among diabetics according to sex and hypoglycaemic treatment given during the course of the diabetes mellitus

\begin{tabular}{|c|c|c|c|c|}
\hline \multirow[b]{2}{*}{$\begin{array}{l}\text { Hypoglycaemic } \\
\text { treatment }\end{array}$} & \multicolumn{2}{|l|}{ Male } & \multicolumn{2}{|l|}{ Female } \\
\hline & $\begin{array}{l}\text { Person-years } \\
\mathrm{n}\end{array}$ & SMR & $\begin{array}{l}\text { Person-years } \\
\text { n }\end{array}$ & SMR \\
\hline Insulin & 1896 & 8.5 & 2273 & 6.2 \\
\hline Oral agents & 7066 & 9.2 & 8664 & 2.5 \\
\hline Diet & 785 & 5.4 & 1096 & 0.8 \\
\hline
\end{tabular}

SMR - age standardised mortality rates on 1000 person-years. Number of observed deaths in each group of person-years of hypoglycaemic treatment are presented in Figure $2 \mathrm{~B}$

the group of patients treated with insulin, intermediate values in the group treated with oral drugs, and lowest in the group managed with diet only, in men as well as in women. The differences in the numbers of predicted and observed deaths between the various treatment groups were statistically significant for both sexes (Fig. 1).

Excess mortality from cardiovascular diseases was analyzed similarly, taking into account initial treatment as well as treatment during the course of the diabetes. With respect to coronary heart disease in men, excess mortality was not related to initial

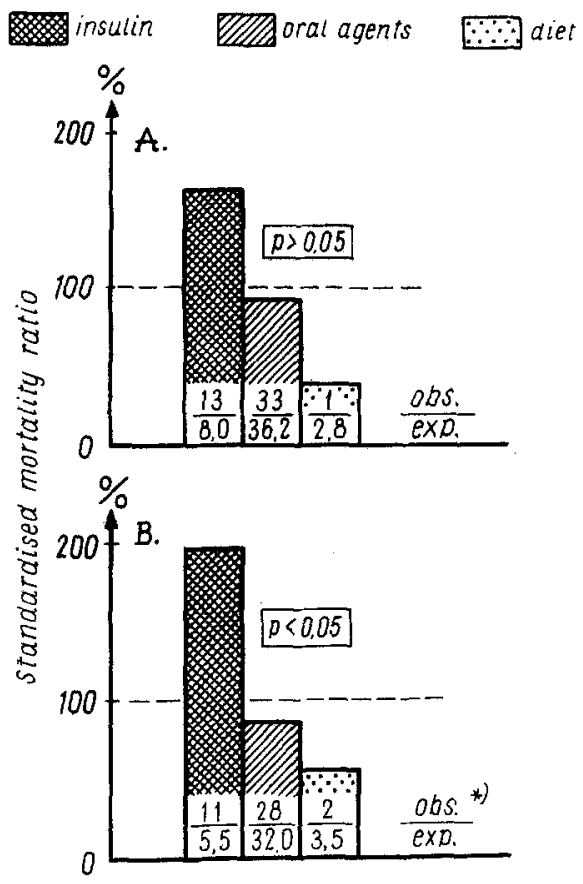

Fig. 3. Standardised mortality ratios from cerebrovascular disease among diabetics according to $\mathrm{A}$ ) initial hypoglycaemic treatment, B) hypoglycaemic treatment applied during the course of diabetes. * Five deaths among men and one among women occurred when treatment was not known and they were excluded from analysis

treatment or to treatment during the course of the diabetes (Fig. 2). Among women, greatest excess mortality was in the group treated initially or during the course of the diabetes with insulin. Intermediate values were observed in the group treated with oral drugs, and lowest values in the group treated only with diet. Differences in predicted and observed numbers of deaths between different treatment groups were statistically significant for both initial and subsequent treatment (Fig. 2).

In order to compare excess mortality from coronary heart disease between men and women within comparable treatment groups, mortality rates standardised for age were calculated in relation to patient-years of hypoglycaemic treatment (Table 4).

The sex difference was lowest in insulin treated patients, women being similar to men among all groups. In the oral agents group, male excess mortality exceeded that of females by a factor of 3.7 , whereas in the dietary treatment group the male excess mortality was increased 6.8 fold.

Excess mortality from cerebrovascular disease was also related to the type of hypoglycaemic therapy in both sexes, but no sex-treatment interaction of the kind described above for coronary heart disease was apparent. Hence, the results in men 
were combined with those in women, and are represented in Figure 3. Highest excess mortality from cerebrovascular disease was observed in the group of patients treated with insulin, intermediate in the group treated with oral agents, and lowest in the dietary group. This was observed in relation to the initial treatment as well as to the treatment during the course of the diabetes.

Differences in the numbers of observed and predicted deaths between the treatment groups were statistically significant only if excess mortality was analyzed in relation to treatment during the course of the diabetes.

\section{Discussion}

The discovery of insulin and its use in the treatment of diabetes, as well as sulphonamides and antibiotics have dramatically reduced the number of deaths from acidotic coma, infection and surgery. The use of these highly effective drugs has prolonged the average expectation of life of diabetics, but it has simultaneously revealed other problems related to vascular complications [1-4].

Kessler found that in the cohort of Joslin Clinic diabetic patients excess mortality was mainly due to cardiovascular diseases [5]. The longitudinal studies in Framingham showed that excess mortality from cardiovascular complications in diabetes was twice as high in men and four times as high in women [8].

The study carried out in Warsaw has also confirmed a two times higher excess mortality from cardiovascular diseases in diabetics compared with the general population of Warsaw. In contrast, however, to results of other studies $[5,8]$ the excess mortality was higher in men than in women. No apparent cause for this was found.

Excess mortality from cardiovascular diseases in diabetic patients in comparison with the normal population may be either due to higher case fatality from myocardial infarction and stroke in diabetics, or higher prevalence of cardiovascular diseases among diabetics, or both. Some clinical observations indicate that hospital mortality from myocardial in farction in diabetics is twice as high as in non-diabetic patients $[9,10]$. It has also been shown that the higher hospital death rate is not due to more frequent complications of myocardial infarction but is the result of more severe outcome of complications when they are present. This is particularly true for cardiac arrhythmias and disorders of conduction (paper in preparation).

So far no similar studies on the clinical course of cerebrovascular events in diabetic patients seem available. However, case fatality from stroke is probably higher in diabetics compared with nondiabetics.

A high prevalence of cardiovascular diseases in diabetics has been found in numerous studies, and has been attributed to a greater prevalence of cardiovascular risk factors coexisting with diabetes or developing during the course of this disease $[8,11$, $12,14]$. A significant excess of cardiovascular conditions has been attributed to hyperglycaemia and concomitant metabolic disturbances [13]. Many authors found that hyperglycaemia predisposes to cardiovascular complications, particularly in women [8, $11,12,14]$. In Warsaw we found that mortality from coronary heart disease was especially high in insulindependent female diabetics. Mortality in this group was similar to that found in males. It may be concluded that in the presence of insulin treatment, diabetic women are prone to arteriosclerotic lesions in the heart to the same degree as male diabetics. Clarification of these problems requires further investigation, particularly to the problem of diabetes increasing the risk of death from cardiovascular diseases, especially if onset of diabetes is early.

At the beginning of the 1970s, a group of American universities (UGDP) reported studies indicating that oral antidiabetic drugs when given to diabetic patients increase the risk of cardiovascular death [16-18]. It may be assumed that if these drugs markedly enhance the chance of death, excess mortality from cardiovascular diseases in the group of patients treated with these drugs should be much higher than in the remaining therapy groups both in men and women. Our results, however, do not confirm this assumption or the results of UGDP. This is not to say that these findings invalidate the conclusions reached by UGDP since the research models, methods and populations differ in both investigations. In addition, in the present study small deleterious effects of oral drugs could be missed because of inclusion of some stronger factors such as insulin-dependency among women or cardiovascular risk factors in males.

Acknowledgements. This investigation was supported in part by Research Grant from POLFA, Poland.

\section{References}

1. Marble, A.: Coronary artery disease in diabetics. Diabetes 4, 290-301 (1955)

2. Entmacher, P.S., Root, H.F., Marks, H.H.: Longevity of diabetic patients in recent years. Diabetes 13, 373-388 (1964)

3. Marks, H.H.: Longevity and mortality of diabetics. Am. J. Public Health 55, 416-423 (1965) 
4. Marks, H. H., Krall, L.P.: Onset course, prognosis and mortality in diabetes mellitus. In: A. Marble, P. White, R.F. Bradley, L.P. Krall (Eds.): Joslin's Diabetes Mellitus, chap. 9, 11th edition. Philadelphia: Lea and Febiger 1971

5. Kessler, I. I.: Mortality experience of diabetic patients. A twenty six year follow-up study. Am. J. Med. 51, 715-724 (1971)

6. Czyzyk, A., Brzeziński, Z.J., Królewski, A.S., Janeczko, D., Wysocki, M., Puncewicz, B.: Losy chorych na cukrzycę. I. Plan badań, metody i grupa badana. Przegl. Epidemiol. 29, 449-459 (1975)

7. Keys, A.: Coronary heart disease in seven countries. Circulation 41, 42 (Suppl. 1), 138-144 (1970)

8. Garcia, M. J., McNamara, P.M., Gordon, T., Kannell, W. B.: Morbidity and mortality in diabetics in the Framingham population. Sixteen year follow-up study. Diabetes 23, 105-111 (1974)

9. Soler, N.G., Pentecost, B.L., Bennett, M. A., Fitzgerald, M. G., Lamb, P., Malins, J. M.: Coronary care for myocardial infarction in diabetics. Lancet $1974 \mathrm{I}, 475-477$

10. Królewski, A.S., Janeczko, D., Kobryń, A., Puncewicz, B.: Survival after myocardial infarction in diabetic patients. I. Hospital mortality. Acta Med. Pol. 16, 45-52 (1975)

11. Kannell, W.B., Castelli, W.P., McNamara, P.M.: The coronary profile: 12-year follow-up in the Framingham study. J. Occup. Med. 9, 611-619 (1967)

12. Epstein, F.H.: Some uses of prospective observations in the Tecumseh Community Health Study. Proc. R. Soc. Med. 60, 56-61 (1967)
13. Epstein, F.H.: Glucose intolerance and coronary heart disease incidence-recent observations In: R. Levine, E. F. Pfeiffer (Eds.): Lipid metabolism, obesity and diabetes mellitus: impact upon atherosclerosis, pp. 174-180. Stuttgart: Georg Thieme 1974

14. Jarrett, R.J.: Diabetes, hyperglycemia and arterial disease. Acta Diábetol. Lat. 8 (Suppl. 1), 7-11 (1971)

15. University Group Diabetes Program: A study of the effects of hypoglycemic agents on vascular complications in patients with adult-onset diabetes. II. Mortality results. Diabetes 19, (Suppl. 2), 789-830 (1970)

16. University Group Diabetes Program: Effects of hypoglycemic agents on vascular complications in patients with adult onset diabetes. IV. A preliminary report on phenformin results. JAMA 217, 77-84 (1971)

17. University Group Diabetes Program: A study of the effects of hypoglycemic agents on vascular complications in patients with adult-onset diabetes. V. Evaluation of phenformin therapy. Diabetes 24, (Suppl. 1), 65-112 (1975)

Received: December 7, 1976 and in revised form: March 26, 1977

Dr. A. S. Królewski

Department of Epidemiology

Medical Academy in Warsaw

ul. Oczki 3

02-007 Warsaw

Poland 